\title{
Bacteremia Caused by a Swallowed Toothpick Impacted in the Gastric Mucosa
}

\author{
Ante Tonkic ${ }^{\mathrm{a}}$ Drago Kulic ${ }^{\mathrm{a}}$ Mari Peric ${ }^{\mathrm{b}}$ Marija Tonkic \\ Zoran Bogdanovic ${ }^{a}$ \\ aDepartment of Internal Medicine, Division of Gastroenterology, and Departments \\ of ${ }^{b}$ Radiology and ${ }^{c} \mathrm{Clinical}$ Microbiology, University Hospital Split, Split, Croatia
}

\section{Key Words}

Bacteremia - Gastric mucosa - Toothpick · Computed tomography · Flexible endoscopy

\begin{abstract}
Although most ingested foreign bodies usually pass through the gastrointestinal tract asymptomatically, toothpick injury to the gastrointestinal tract is often associated with significant morbidity and mortality. Toothpick perforation of the gastrointestinal tract is frequently reported but, to the best of our knowledge, bacteremia caused by an impacted toothpick within the gastric mucosa has not yet been described. Here, we report the case of bacteremia caused by an accidentally swallowed toothpick. The toothpick was impacted deeply in the gastric mucosa and was first seen and localized on contrast-enhanced computed tomography (CT). CT scan is a very useful imaging technique in such situations since we lack typical and relevant physical findings or laboratory studies that go with accidentally swallowed objects, in this case a toothpick. Flexible endoscopy was successful in extracting the whole toothpick. In cases without free perforation, flexible endoscopy is the treatment of choice in toothpick removal from the upper gastrointestinal tract.
\end{abstract}

\section{Introduction}

Although in most cases (80-90\%) the ingested foreign body will pass uneventfully through the gastrointestinal tract, sharp foreign bodies such as toothpicks are associated with an increased risk of gastrointestinal perforation and bleeding [1]. Toothpicks used for mouth cleansing may be ingested purposefully or accidentally. The most common causes of the accidental ingestion of toothpicks include alcoholism, rapid food intake and decreased palatal sensitivity [2]. Although the complications caused by swallowed toothpicks are more likely to be detected and resolved by surgical procedure in selected 
cases when it is possible to locate the position of the toothpick, endoscopic removal can result in the rapid relief of symptoms $[3,4]$.

\section{Case Report}

A 57-year-old Caucasian woman with no previous medical history was admitted to the Department of Internal Medicine, Division of Gastroenterology, Clinical Hospital Split. She complained of fever and abdominal pain located in right upper quadrant for one week. Vital signs were as follows: blood pressure $120 / 80 \mathrm{~mm} \mathrm{Hg}$, pulse rate $100 \mathrm{bpm}$ and core body temperature $39.0^{\circ} \mathrm{C}$. Chest and heart examinations were normal. The abdomen was soft and without tenderness. The liver and spleen were not palpable. Laboratory evaluation revealed a WBC count of $12.5 \times 10^{9} / 1$ with a left shift and C-reactive protein concentration of $123.6 \mathrm{mg} / \mathrm{l}$ while urinalysis as well as other relevant laboratory data were within reference values. Baseline laboratory values on admission are outlined in table 1 . Blood cultures drawn on the first hospital day grew methicillin-susceptible Staphylococcus aureus. Plain abdominal film was normal. Abdominal ultrasound examination was performed because of a clinical presentation mimicking acute cholecystitis, but it was within normal ranges. However, contrast-enhanced computed tomography (CT) scan with three-phase protocol showed an unclearly outlined lesion within the liver parenchyma with a longer diameter of $2.1 \mathrm{~cm}$ and which could not be clearly separated from eccentric radiopaque thickening of the stomach antrum in an extension of more than $4 \mathrm{~cm}$ (fig. 1, fig. 2). This finding indicated gastroscopy, which revealed a sharp wooden foreign body protruding from the antrum mucosa and the whole wooden foreign body (toothpick) was successfully removed by snare extraction without complications. After the extraction of the foreign body the patient remembered that two weeks earlier when consuming lamb she might possibly have swallowed a toothpick.

The patient was also treated with a proton pump inhibitor (pantoprasole), the intravenous administration of crystalloids and ceftriaxone for seven days. A control gastroscopy performed a week later revealed complete healing of the gastric mucosa. The patient was dismissed from hospital after one week in good clinical condition.

\section{Discussion}

The majority of swallowed indigestible foreign bodies pass through the gastrointestinal tract without complications [2]. The major complications caused by ingested foreign bodies are obstruction, perforation or bleeding [2]. Impaction, perforation and obstruction most often occur in areas of acute angulation or physiologic narrowing. It is difficult to estimate the incidence of accidental ingestion of toothpicks, mostly because the literature covering this issue is anecdotal. In contrast to this, it is well known that toothpick lesions to the gastrointestinal tract are often associated with significant morbidity and mortality [2-4]. Clinical presentation of toothpick gastrointestinal injury includes generalized or local peritonitis, intestinal obstruction or gastrointestinal hemorrhage. In some cases toothpicks migrated outside the gastrointestinal tract and were found in the pleura, pericardium, ureter or bladder [2, 5-7]. Ingested toothpicks in the esophagus and small intestines are presented by dysphagia or intestinal colic while foreign objects remaining in the stomach are often asymptomatic. Early diagnosis and retrieval of the toothpick is critical for reducing morbidity and mortality $[3,8,9]$. Therefore, we think that a patient presenting with Gram-positive bacteremia and no sign of free perforation of the gastrointestinal tract is very illustrative because this demonstrates the necessity of thinking of foreign body ingestion as a cause of obscure bacteremias.

We would like to emphasize how important it is to make a very careful anamnesis in order to determine swallowed foreign objects, such as a toothpick, as a rare cause of 
bacteremia. Moreover, there are no relevant physical or laboratory findings characteristic for a swallowed toothpick. CT images are useful in acquiring missing clinical information such as toothpick location. In cases without free perforation, flexible endoscopy is the treatment of choice for upper gastrointestinal toothpick removal.

Table 1. Patient's laboratory parameters on admission

\begin{tabular}{lll}
\hline Parameter & Patient value & Normal range \\
\hline Red blood cells, $\times 10^{12} / 1$ & 4.5 & $4.2-6.3$ \\
White blood cells, $\times 10^{9} / 1$ & 12.5 & $4.5-11.0$ \\
Hemoglobin, g/l & 115 & $120-180$ \\
Hematocrit, \% & 35 & $37-51$ \\
Mean corpuscular volume, fl & 78.2 & $80-97$ \\
Platelet count, $\times 10^{9} / 1$ & 239 & $100-350$ \\
C-reactive protein, mg/l & 123.6 & $<5$ \\
Glucose, mmol/l & 6.0 & $3.5-6.5$ \\
Creatine, $\mu$ mol/l & 58 & $54-116$ \\
Sodium, mmol/l & 137 & $135-145$ \\
Potassium, mmol/l & 4.4 & $3.5-5.1$ \\
Chloride, mmol/l & 99 & $90-108$ \\
Aspartate aminotransferase, IU/1 & 11 & $1-38$ \\
Alanine aminotransferase, IU/l & 17 & $1-41$ \\
Lactate dehydrogenase, IU/l & 380 & $160-460$ \\
Gamma-glutamyl transferase, IU/l & 60 & $8-52$ \\
Bilirubin, $\mu$ mol/l & 13.0 & $17-20$ \\
Total proteins, g/l & 66 & $60-80$ \\
\hline
\end{tabular}




\begin{tabular}{c|l|l|l}
$\begin{aligned} \text { Case Reports in } & \begin{array}{l}\text { Case Rep Gastroenterol 2011;5:227-231 } \\
\text { DOl: 10.1159/000327974 }\end{array}\end{aligned}$ & $\begin{array}{l}\text { Published online: } \\
\text { April 15, 2011 }\end{array}$ & $\begin{array}{l}\text { O 2011 S. Karger AG, Basel } \\
\text { ISSN 1662-0631 } \\
\text { www.karger.com/crg }\end{array}$ \\
\hline
\end{tabular}

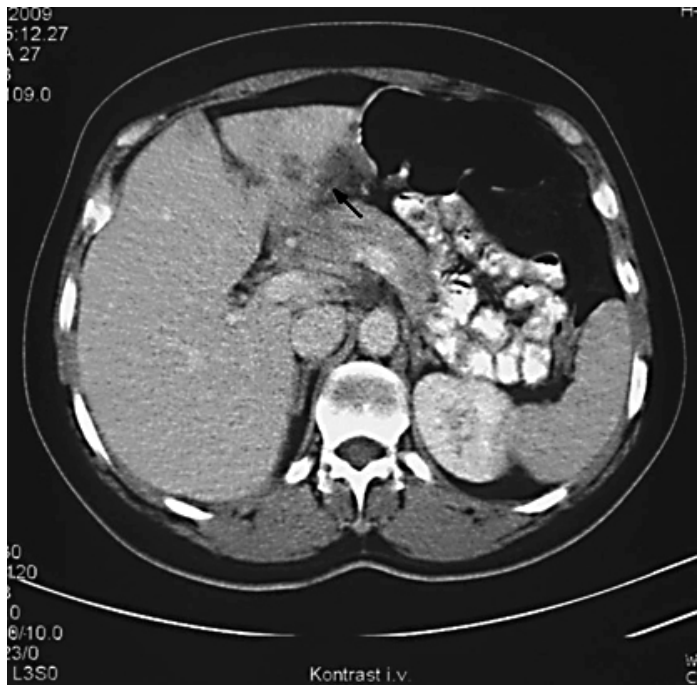

Fig. 1. Axial contrast-enhanced abdominal CT scan showing a significant thickening in the medial aspect of the gastric antrum which is difficult to separate from the hypodense lesion in the left liver lobe. In this thickened area of the stomach wall there is a narrow tubular structure (arrow) suspicious of foreign body.

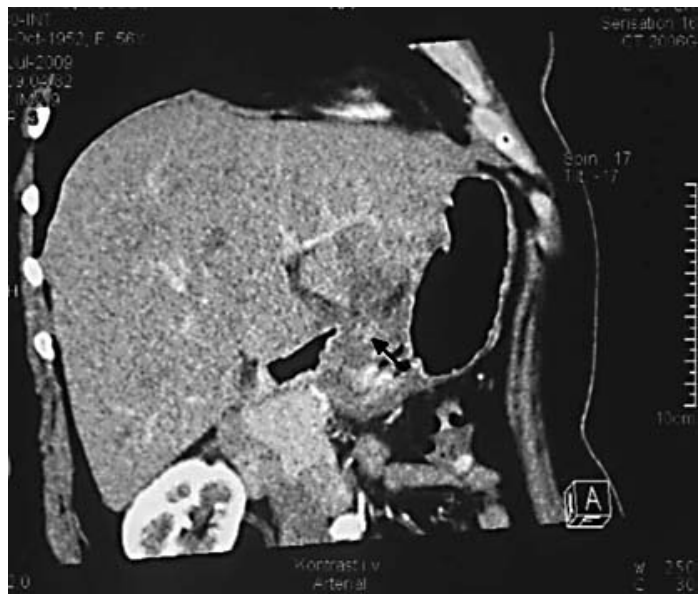

Fig. 2. Contrast-enhanced CT scan after reconstruction showing a hypodense area in the liver extending to the thickened medial wall of the gastric antrum, containing a narrow hyperdense tubular structure foreign body (arrow). 


\begin{tabular}{r|l|l|l}
$\begin{aligned} \text { Case Reports in } \\
\text { Gastroenterology }\end{aligned}$ & $\begin{array}{l}\text { Case Rep Gastroenterol 2011;5:227-231 } \\
\text { Dol: 10.1159/000327974 }\end{array}$ & $\begin{array}{l}\text { Published online: } \\
\text { April 15, 2011 }\end{array}$ & $\begin{array}{l}\text { O 2011 S. Karger AG, Basel } \\
\text { ISSN 1662-0631 } \\
\text { www.karger.com/crg }\end{array}$ \\
\hline
\end{tabular}

\section{References}

1 Smith MT, Wong RK: Foreign bodies. Gastrointest Endosc Clin N Am 2007;17:361-382.

2 Schwartz JT, Graham DY: Toothpick perforation of the intestines. Ann Surg 1977;185:64-66.

-3 Ayantunde AA, Oke T: A review of gastrointestinal foreign bodies. Int J Clin Pract 2006;60:735-739.

4 Matsubara M, Hirasaki S, Suzuki S: Gastric penetration by an ingested toothpick successfully managed with computed tomography and endoscopy. Intern Med 2007;46:971-974.

5 Cockerill FR, Wilson WR, Van Scoy RE: Traveling toothpicks. Mayo Clin Proc 1983;58:613-616.

6 Nigri GR, Di Giulio E, Di Nardo R, et al: Duodenal perforation and right hydronephrosis due to toothpick ingestion. J Emerg Med 2008;34:55-57.

7 Li SF, Ender K: Toothpick injury mimicking renal colic: case report and systematic review. J Emerg Med 2002;23:35-38.

8 Tenner S, Wong RC, Carr-Locke D, Davis SK, Farraye FA: Toothpick ingestion as a cause of acute and chronic duodenal inflammation. Am J Gastroenterol 1996;91:1860-1862.

$\checkmark 9$ Conway WC, Sugava C, Ono H, Lucas CE: Upper GI foreign body: an adult urban emergency hospital experience. Surg Endosc 2007;21:455-460. 